\title{
Buckling and Post-buckling Analysis of Composite Plates
}

\author{
Elena-Felicia Beznea and Ionel Chirica \\ University Dunarea de Jos of Galati \\ Romania
}

\section{Introduction}

Thin walled stiffened composite panels are among the most utilized structural elements in ship structures. The composite layered panels with fibers are the most usually used in shipbuilding, aerospace industry and in engineering constructions as well. These structures possess the unfortunate property of being highly sensitive to geometrical and mechanical imperfections. These panels, unfortunately, have one important characteristic connected to big sensitivity on geometrical imperfections (different dimensions comparative with the design ones). The defects are of following types: different directions of fibers design, variations in thickness, inclusions, delaminations or initial transversal deformations.

Ship structure plates are subjected to any combination of in plane, out of plane and shear loads during application. Due to the geometry and general load of the ship hull, buckling is one of the most important failure criteria of these structures.

This is why it is necessary to develop the appropriate methodologies able to correctly predict the behavior of a laminated composite plate in the deep postbuckling region, at the collapse load, which is characterized by separation between the skin and the stiffeners, delaminations, crack propagations and matrix failure, as well as to understand its behavior under repeated buckling.

During its normal service life, a ship hull, which is composed of many curved laminated composite stringer stiffened panels, may experience a few hundreds of bucklingpostbuckling cycles. Although it is well recognized that CFRP stiffened structures are capable of withstanding very deep post-buckling, yielding collapse loads equal to three four times their buckling load (Bisagni \& Cordisco, 2004, Knight \& Starnes, 1988), there exists scarce knowledge in the literature about the effects of repeated buckling on the global behavior of the laminated composite panels under combined loading influences.

According to the studies, it is possible to predict on how far into the post-buckling region it is possible to increase loading without loosing structural safety.

Buckling failure mode of a stiffened plate can further be subdivided into global buckling, local skin buckling and stiffener crippling. Global buckling is collapse of the whole structure, i.e. collapse of the stiffeners and the shell as one unit.

Local plate buckling and stiffeners crippling on the other hand are localized failure modes involving local failure of only the skin in the first case and the stiffener in the second case. A grid stiffened panel will fail in any of these failure modes depending on the stiffener configuration, plate thickness, shell winding angle and type of applied load. 
Over the past four decades, a lot of research has been focused on the buckling, collapse and post buckling behavior of composite shells. The simplest stiffened panel consists of only orthogonal stiffeners (stiffened orthogrid) such as longitudinal and transversal girders.

Another type of stiffener arrangement is the transversal framing system.

Different analytical tools have so far been developed by researches to successfully predict the three buckling failure modes associated with stiffened panels subjected to different loading conditions.

The use of finite-elements analysis for investigation of buckling problem of composite panels is becoming popular due to the improvement in computational hardware and emergence of highly specialized software. Depending on the degree of accuracy desired and limit of computational cost, three types of buckling analysis can be carried out. Linear bifurcation analysis is the basic analysis type which does not take into consideration the prebuckling deformation and stresses. This analysis can accurately predict the buckling load of a geometrically perfect compression loaded panel, and the pre-buckling deformation and stress in the panel have an insignificant effect on the predicted bifurcation buckling load of the shell. The second kind of bifurcation analysis takes into consideration the nonlinear prebuckling deformation and stresses and results in a much more accurate buckling load.

The third analysis, the nonlinear buckling analysis, allows for large nonlinear geometric deflections. Unlike the previous two bifurcation analyses that are eigenvalue problems, the nonlinear analysis is iterative in nature. In this analysis the load is steadily increased until the solution starts to diverge.

In this chapter, layered composite plates with imperfections are analysed.

\subsection{Plates with initial imperfection}

The composite layered panels with fibers are the most usually used in shipbuilding industry and in engineering constructions as well. Taking into account that fabrication technologies of composite materials are hand made based, the probabilistic occurrence of defects is quite too high. These panels, unfortunately, have one important characteristic connected to big sensitivity on geometrical imperfections (initial transversal deformation).

In this chapter is analyzing the buckling behavior of the plates placed between two pairs of stiffeners of the ship hull structure. Objective is to present the results obtained after buckling analysis of ship hull plates made of composite materials taking into account the transversal imperfection (spatial cosine form) due to fabrication. Due to the special behavior of the layered composite plates, the nonlinear analysis of the buckling behavior of the plates is to do. In certain cases, to determine the buckling load (ultimate strength), the failure criterion is applied. The buckling load is determined when the first failure occures in an element, based on the Tsai-Wu failure criterion, who provides the mathematical relation for the strength under combined stresses.

\subsection{Plates with delaminations}

Delamination in composite structures can be a serious threat to the safety of the structure.

Delamination leads to loss of stiffness and strength of laminates under some conditions. This is particularly so in the case of compressively loaded structures as the loss of stiffness may lead to buckling, the consequences of which can be catastrophic.

Causes of delamination are many. In shipbuilding and aerospace applications, this includes manufacturing defects, as well as operationally induced defects such as bird strikes hits due 
to runway debris and tool drops (aerospace), or cargo operating and slamming loading (shipbuilding).

The type of delamination that is dealt with in this report is the one that is already initiated by one of the above causes.

When a laminate is subjected to in-plane compression, the effects of delamination on the stiffness and strength may be characterised by three sets of analytical results:

a. Buckling load;

b. Post-buckling solutions under increased load;

c. Results concerning the onset of delamination growth and its subsequent development.

Many of the analytical treatments deal with a thin near surface delamination. Such approaches are known as "thin-film" analysis in the literature. The thin-film analytical approach may involve significant errors in the post-buckling solutions.

\section{Theory, finite element and experimental modeling of perfect composite plates}

The buckling of composite plates is treated with specific methods applied to each particular case. This part deals with classical bifurcation and FEM buckling analysis, discusses the relevant plate equations and their solutions and edge conditions for perfect plates. The buckling phenomena mean collapse of the structure at the maximum point in a load versus deflection curve and bifurcation buckling. The way in which buckling occurs depends on how the structure is loaded and on its geometrical and material properties. The prebuckling process is often nonlinear if there is a large bending energy being stored in the structure throughout the loading history. According to the level of bending energy, the buckling of plates can occur in two ways: the first is bifurcation buckling and the second is limit point buckling. Bifurcation buckling is an instability in which there is a sudden change of shape of the structure. A bifurcation point is a point in a load-deflection space where two equilibrium paths intersect. On a load-frequency curve, a bifurcation point can be characterized by the load-frequency curve passing through a frequency of zero with a non-zero slope.

Limit point buckling is an instability in which the load-displacement curve reaches a maximum and then exhibits negative stiffness and releases strain energy. During limit point buckling there are no sudden changes in the equilibrium path; however, if load is continuously increased then the structure may jump or "snap" to another point on the loaddeflection curve. For this reason, this type of instability is often called "snap-through" buckling, because the structure snaps to a new equilibrium position. A limit point is characterized by the load-frequency curve passing through a frequency of zero with a zero slope. The load-deflection curve also has a zero slope at the point of maximum load (limit point).

Buckling analysis of a plate may be divided into three parts:

- Classical buckling analysis;

- Difficult classical effects;

- Non classical phenomena.

The classical buckling theory may be described by the curve 1-3, from the Fig. AA1 where is plotted the in-plane loading force $(N)$ versus the transversal displacement $(w)$ of a representative point of the plate. By supposing that the loading is applied in the median plane of the plate, no transversal displacement will occur, and in the conditions of perfect symmetry the loading may increase up to the yield point, according to the curve 1-2. At a 
value over the $N_{\text {cr }}$, the instability may occur. At $N=N_{\text {cr }}$ one bifurcation point does exist. This means that on the curve loading-displacement, on the path 4 , other way, much stable for buckling occurring does exist. At the value $N_{\mathrm{cr}}$ a little perturbation will generate a transversal displacement.

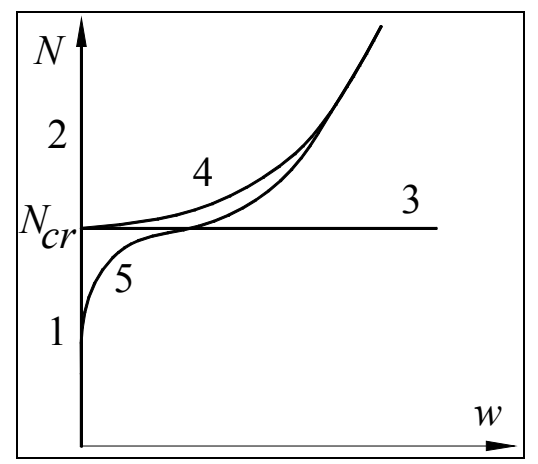

Fig. 17.1. Variation of transversal displacement, $w$, of a plate's point versus in-plane load $N$

The classical linear analysis, which is a generalization of the Euler buckling for beams, should indicate the fact that $w$ increases to infinite at $N=N_{\text {cr }}$ (curve 3). Really, the nonlinear effects started to act and after an initial finite displacement, the in-plane loading $N$ is increasing since the displacement is increasing. In this case the plate is able to carry loads far in excess of $N_{\text {cr }}$ before it collapse. The latest curve (4) is so called a "postbuckling curve" because it depicts the behaviour of the plate after the buckling load $N_{\mathrm{cr}}$ is reached.

The difficult effects in classical buckling analysis are in connection with vibrations, shear deformations, springs, non homogeneities and variable thicknesses, nonlinear relations between stresses and strains. Non classical buckling analysis involves considerations such as imperfections, non-elastic behaviour of the material, dynamic effects of the loading, the fact that the in-plane loading is not in the initial point of the plate.

Finally, it may point out that no plate is initially perfect (perfectly flat or perfectly symmetry) and if initial deviation (from flatness or symmetry) exists, the behaviour of the plate will follow the path similar with curve 1-5. In this case, no clear buckling phenomenon may be identifying. The deviations of the plate from the flatness and symmetry are usually called imperfections (initial transversal imperfections, delaminations) as it will be treated in the following chapters.

The following cases (in numerical and experimental ways) are presented: compressive buckling, shear buckling, mixed compressive and shear buckling. The results (for linear and nonlinear model) are presented as variation of the buckling loads function of maximum transversal displacement (buckling and post-buckling behaviour).

The state of equilibrium of a plate deformed by forces acting in the plane of the middle surface is unique and the equilibrium is stable if the forces are sufficiently small. If, while maintaining the distribution of forces constant at the edge of the plate, the forces are increased in magnitude, there may arise a time when the basic form of equilibrium ceases to be unique and stable and other forms become possible, which are characterized by the curvatures of the middle surface.

The equation of the deflected surface of symmetrically laminated plates is 


$$
\begin{aligned}
& D_{11} \frac{\partial^{4} w}{\partial x^{4}}+4 D_{16} \frac{\partial^{4} w}{\partial x^{3} \partial y}+2\left(D_{12}+D_{66}\right) \frac{\partial^{4} w}{\partial x^{2} \partial y^{2}}+4 D_{26} \frac{\partial^{4} w}{\partial x \partial y^{3}}+D_{22} \frac{\partial^{4} w}{\partial y^{4}}- \\
& -N_{x} \frac{\partial^{2} w}{\partial x^{2}}-2 N_{x y} \frac{\partial^{2} w}{\partial x \partial y}-N_{y} \frac{\partial^{2} w}{\partial y^{2}}=0
\end{aligned}
$$

For symmetrically laminated cross-ply plates there is no coupling between bending and twisting. So, $\mathrm{D}_{16}=\mathrm{D}_{26}=0$. In this case, the equation (AA1) will have the form as the buckling equation for a homogeneous, orthotropic plate

$$
D_{11} \frac{\partial^{4} w}{\partial x^{4}}+2\left(D_{12}+D_{66}\right) \frac{\partial^{4} w}{\partial x^{2} \partial y^{2}}+D_{22} \frac{\partial^{4} w}{\partial y^{4}}-N_{x} \frac{\partial^{2} w}{\partial x^{2}}-2 N_{x y} \frac{\partial^{2} w}{\partial x \partial y}-N_{y} \frac{\partial^{2} w}{\partial y^{2}}=0
$$

where $D_{11}, D_{22}, D_{66}, D_{16}, D_{26}$ are the orthotropic plate stiffnesses, calculated according to the equation

$$
D_{i j}=\frac{1}{3} \sum_{k=1}^{N} \bar{Q}_{i j}^{k}\left(\bar{z}_{k}^{3}-\bar{z}_{k-1}^{3}\right)
$$

The thickness and position of every ply can be calculated from the equation

$$
t_{k}=z_{k}-z_{k-1}
$$

and

$$
\bar{z}_{k}=z_{k-1}+\frac{t_{k}}{2}
$$

The second and fourth terms from equation (AA2) are the measure of the orthotropic coupling, resulting from the fact that the principal orthotropic axes are not orthogonal with the plate geometry axes.

Linear buckling of beams, membranes and plates has since been studied extensively. A linearized stability analysis is convenient from a mathematical viewpoint but quite restrictive in practical applications. What is needed is a capability for determining the nonlinear load-deflection behaviour of a structure. Considerable effort has also been expended on this problem and two approaches have evolved: class-I methods, which are incremental in nature and do not necessarily satisfy equilibrium; and class-II methods, which are self-correcting and tend to stay on the true equilibrium path (Thurley \& Marshal, 1995).

Historically, class-I was the first finite element approach to solving geometrically non-linear problems (Ambarcumyan, 1991). In this method the load is applied as a sequence of sufficiently small increments so that the structure can be assumed to respond linearly during each increment.

To solving of geometrically and material nonlinear problems, the load is applied as a sequence of sufficiently small increments so that the structure can be assumed to respond linearly during each increment.

For each increment of load, increments of displacements and corresponding increments of stress and strain are computed. These incremental quantities are used to compute various corrective stiffness matrices (variously termed geometric, initial stress, and initial strain 
matrices) which serve to take into account the deformed geometry of the structure. A subsequent increment of load is applied and the process is continued until the desired number of load increments has been applied. The net effect is to solve a sequence of linear problems wherein the stiffness properties are recomputed based on the current geometry prior to each load increment. The solution procedure takes the following mathematical form

$$
\left(\mathrm{K}+\mathrm{K}_{\mathrm{I}}\right)_{\mathrm{i}-1} \Delta \mathrm{d}_{\mathrm{i}}=\Delta \mathrm{Q}
$$

where

$\mathrm{K}$ is the linear stiffness matrix,

$\mathrm{K}_{\mathrm{I}}$ is an incremental stiffness matrix based upon displacements at load step i-1,

$\Delta \mathrm{d}_{\mathrm{i}}$ is the increment of displacement due to the $\mathrm{i}$-th load increment,

$\Delta \mathrm{Q}$ is the increment of load applied.

The correct form of the incremental stiffness matrix has been a point of some controversy. The incremental approach is quite popular (this is the procedure applied in all studies in this chapter). This is due to the ease with which the procedure may be applied and the almost guaranteed convergences if small enough load increments are used.

The plate material is damaged according to a specific criterion.

For various materials classes three dimensional failure criteria are developed. These include both isotropic and anisotropic material symmetries, and are applicable for macroscopic homogeneity. In the isotropic materials form, the properly calibrated failure criteria can distinguish ductile from brittle failure for specific stress states. Although most of the results are relevant to quasi-static failure, some are for time dependent failure conditions as well as for fatigue conditions.

The buckling load determination may use the Tsai-Wu failure criterion in the case if the general buckling does not occurred till the first-ply failure occurring. In this case, the buckling load is considered as the in-plane load corresponding to the first-ply failure occurring.

The Tsai- $\mathrm{Wu}$ failure criterion provides the mathematical relation for strength under combined stresses. Unlike the conventional isotropic materials where one constant will suffice for failure stress level and location, laminated composite materials require more elaborate methods to establish failure stresses. The strength of the laminated composite can be based on the strength of individual plies within the laminate. In addition, the failure of plies can be successive as the applied load increases. There may be a first ply failure followed by other ply failures until the last ply fails, denoting the ultimate failure of the laminate. Progressive failure description is therefore quite complex for laminated composite structures. A simpler approach for establishing failure consists of determining the structural integrity which depends on the definition of an allowable stress field. This stress field is usually characterized by a set of allowable stresses in the material principal directions.

The failure criterion is used to calculate a failure index (F.I.) from the computed stresses and user-supplied material strengths. A failure index of 1 denotes the onset of failure, and a value less than 1 denotes no failure. The failure indices are computed for all layers in each element of your model. During postprocessing, it is possible to plot failure indices of the mesh for any layer.

The Tsai-Wu failure criterion (also known as the Tsai-Wu tensor polynomial theory) is commonly used for orthotropic materials with unequal tensile and compressive strengths. The failure index according to this theory is computed using the following equation (Altenbach \& all, 2004, Ambarcumyan, 1991). 


$$
\text { F.I. }=\mathrm{F}_{1} \cdot \sigma_{1}+\mathrm{F}_{2} \cdot \sigma_{2}+\mathrm{F}_{11} \cdot \sigma_{1}^{2}+\mathrm{F}_{22} \cdot \sigma_{2}^{2}+\mathrm{F}_{66} \cdot \sigma_{6}^{2}+2 \mathrm{~F}_{12} \cdot \sigma_{1} \cdot \sigma_{2}
$$

where

$$
\mathrm{F}_{1}=\frac{1}{\mathrm{R}_{1}^{\mathrm{T}}}-\frac{1}{\mathrm{R}_{1}^{\mathrm{C}}} ; \mathrm{F}_{11}=\frac{1}{\mathrm{R}_{1}^{\mathrm{T}} \cdot \mathrm{R}_{1}^{\mathrm{C}}} ; \mathrm{F}_{2}=\frac{1}{\mathrm{R}_{2}^{\mathrm{T}}}-\frac{1}{\mathrm{R}_{2}^{\mathrm{C}}} ; \mathrm{F}_{22}=\frac{1}{\mathrm{R}_{2}^{\mathrm{T}} \cdot \mathrm{R}_{2}^{\mathrm{C}}} ; \mathrm{F}_{66}=\frac{1}{\mathrm{R}_{12}^{2}} \text {. }
$$

The coefficient $\mathrm{F}_{12}$, which represents the parameter of interaction between $\sigma_{1}$ and $\sigma_{2}$, is to be obtained by a mechanical biaxial test. In the equations (AA8), the parameters $R_{i}^{C}, R_{i}^{T}$ are the compressive strength and tensile strength in the material in longitudinal direction $(i=1)$ and transversal direction ( $\mathrm{i}=2)$. The parameter $\mathrm{R}_{12}$ is in-plane shear strength in the material 1-2 plane.

According to the Tsai-Wu failure criterion, the failure of a lamina occurs if

$$
\text { F.I. }>1 \text {. }
$$

The failure index in calculated in each ply of each element. In the ply where failure index is greater than 1, the first-ply failure occurs, according to the Tsai-Wu criterion. In the next steps, the tensile and compressive properties of this element are reduced by the failure index. If the buckling did not appeared until the moment of the first-ply failure occurring, the in-plane load corresponding to this moment is considered as the buckling load.

\section{Finite element and experimental modeling of composite plates with initial transversal imperfection}

\subsection{Presentation}

In this part, the buckling behavior of the plates with initial transversal deformation, placed between two pairs of stiffeners of the ship hull structure is analyzing. The results obtained on buckling analysis of ship hull plates made of composite materials taking into account the imperfection due to fabrication, are presented. Due to the special behavior of the layered composite plates, the nonlinear analysis of the buckling behavior of the plates is done. The buckling load is determined according to the first failure occurring in an element, based on the Tsai-Wu failure criterion.

The most used framing construction types for the ship deck plates made of composite materials are transversal or mixed. So, the following case of plate placed in the ship deck structure is analyzed: the plate placed between two pairs of parallel stiffeners (two transversal web frames and two longitudinal frames - longitudinal framing construction system).

The geometry of the plate is square one, having the side length of $320 \mathrm{~mm}$, and total thickness of $4.96 \mathrm{~mm}$. The layers were grouped into the macro-layers (group of layers having the same characteristics: thickness $(t)$, direction of fibers $(\alpha)$ and type of material).

The imperfections of plates are considered the initial transversal deformations. The shape of the deformation is just the first form of the buckling of perfect plate clamped on the sides. The analysis presented in this part is done for the most usual magnitudes of the transversal deformation of the imperfections (versus side length of the plate) occurred in the ship deck plates after fabrication.

The following cases (in numerical and experimental ways) are presented: compressive buckling, shear buckling, mixed compressive and shear buckling. The results (for linear and 
nonlinear model) are presented as variation of the buckling loads function of maximum transversal displacement (buckling and post-buckling behaviour).

The simplest stiffened plate consists of only orthogonal stiffeners (stiffened orthogrid) such as longitudinals and transversal girders. Other type of stiffener arrangement is the transversal framing system.

The characteristics of the material used in this chapter are:

$\mathrm{Ex}=46 \mathrm{GPa}, \mathrm{Ey}=13 \mathrm{GPa}, \mathrm{Ez}=13 \mathrm{GPa}, \mathrm{Gxy}=5 \mathrm{GPa}, \mathrm{G} x z=5 \mathrm{GPa}, \mathrm{Gyz}=4.6 \mathrm{GPa}, \mu_{\mathrm{xy}}=0.3$, $\mu_{\mathrm{yz}}=0.42, \mu_{\mathrm{xz}}=0.3$,

- $\quad$ traction strengths $\mathrm{R}_{\mathrm{x}}=1.062 \mathrm{GPa}, \mathrm{R}_{\mathrm{y}}=0.031 \mathrm{GPa}$,

- compression strength $R_{y}=0.118 \mathrm{GPa}$,

- $\quad$ shear strength $\mathrm{R}_{\mathrm{xy}}=0.72 \mathrm{GPa}$.

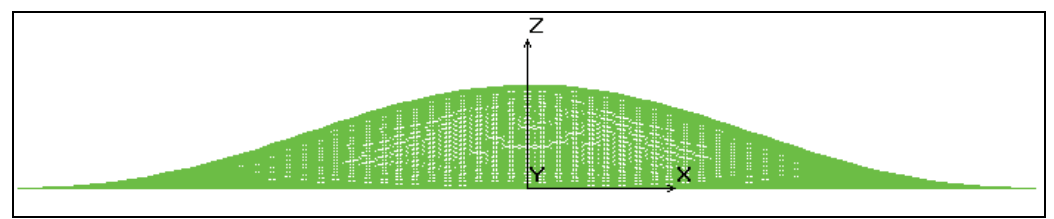

Fig. 17.2. Plate cross section in plane $\mathrm{xz}$

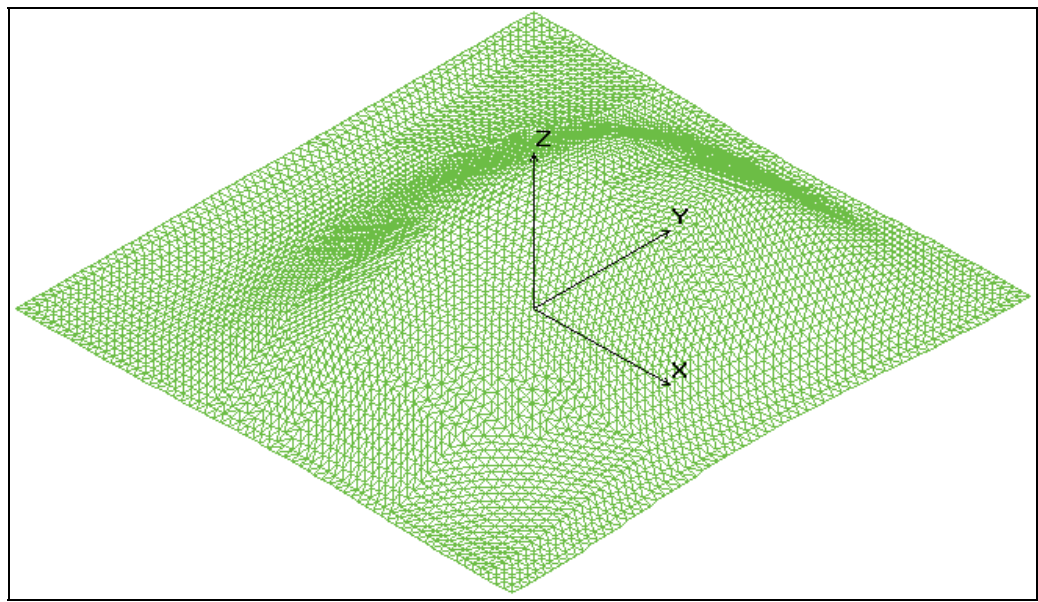

Fig. 17.3. Imperfect plate

Different analytical tools have so far been developed by researches to successfully predict the three buckling failure modes associated with stiffened panels subjected to different loading conditions. These analytical tools developed are divided into three major categories. The use of finite-elements analysis for investigation of buckling problem of composite panels is becoming popular due to the improvement in computational hardware and emergence of highly specialized software. Depending on the degree of accuracy desired and limit of computational cost, three types of buckling analysis can be carried out. Linear bifurcation analysis is the basic analysis type which does not take into consideration the prebuckling deformation and stresses. This analysis can accurately predict the buckling load of a geometrically perfect compression loaded plate, and the pre-buckling deformation and 
stress in the plate have an insignificant effect on the predicted bifurcation buckling load of the shell (Ambarcumyan, 1991, Thurley \& Marshall, 1995). The second kind of bifurcation analysis takes into consideration the nonlinear pre-buckling deformation and stresses and results in a much more accurate buckling load (Adams \& all, 2003, Chirica \& all, 2008).

The third analysis, the nonlinear buckling analysis, allows for large nonlinear geometric deflections. Unlike the previous two bifurcation analyses that are eigenvalue problems, the nonlinear analysis is iterative in nature. In this analysis the load is steadily increased until the solution starts to diverge (Adams \& all, 2003). A lot of work has been done in finite elements analysis pertaining to the investigation of buckling of stiffened panels (Beznea, 2008, Chirica \& all, 2008). One of the major drawbacks associated with this tool is the tedious model-building phase involved and the subsequent inconvenient parametric study.

Following to these considerations, in this chapter the results of the buckling behavior analysing of the plates placed between two pairs of stiffeners of the ship hull structure are analysed. In the following pages only the results obtained after buckling analysis of ship hull plates made of composite materials taking into account the imperfection due to fabrication will be presented. Due to the special behavior of the layered composite plates, the nonlinear analysis of the buckling behavior of the plates is to do (Altenbach, 2004, Hilburger, 2001).

\subsection{Numerical studies on compression buckling}

The most used framing construction types for the ship deck panels made of composite materials are transversal or mixed. So, in this chapter the following case is presented (case of plates placed in the ship deck structure): plate placed between two pairs of parallel stiffeners ( 2 transversal web frames and 2 longitudinal frames, in the case of longitudinal framing construction system);

The geometry of the plates is square one, having the side length of $320 \mathrm{~mm}$, and total thickness of $4.96 \mathrm{~mm}$ respectivelly. The orthotropic directions $(\alpha)$, thickness of the macrolayers ( $t$ ) and plate lay-up are presented in Table AA1. The layers were grouped into the macro-layers (group of layers having the same characteristics: thickness $(t)$, direction of fibers $(\alpha)$ and type of material).

The constrains are considered according to each plate. The degrees of freedom (displacements $u$ and rotations $r$ ), considered to be zero are:

- $\quad$ on the sides parallel with $x$ axis: $\mathrm{u}_{\mathrm{z}}, \mathrm{r}_{\mathrm{x}}, \mathrm{r}_{\mathrm{y}}$;

- $\quad$ on the sides parallel with y axis: all d.o.f. (clamped side); $u_{y}, u_{z}, r_{x}, r_{y}, r_{z}$ (charged side).

The shape of the initial transversal deformation is considered as just the first form of the buckling of perfect plate clamped on the sides (Figures AA2 and AA3).

The analysis presented in this chapter is done for the most usual magnitudes $\left(\mathrm{w}_{0}\right)$ of the transversal deformation of the imperfections (versus side length of the plate) occurred in the ship deck plates after fabrication. The following three cases are considered: $\mathrm{w}_{0}=1.06 \mathrm{~mm}$ (symbol 12); $\mathrm{w}_{0}=3.2 \mathrm{~mm}$ ( symbol 32); $\mathrm{w}_{0}=9.6 \mathrm{~mm}$ ( symbol 92$)$.

In figures AA2 and AA3 the FEM model using shell composite elements is presented. In figure AA4, the variation of the transversal displacement of the middle point of the plate versus in-plane loading magnitude for the plate is plotted.

Since the plates have initial transversal deformation, as it is seen in the figure AA4 the increasing of the transversal deformation is starting from the beginning, which is so named buckling is starting as the in-plane load is starting to increase from 0 . 


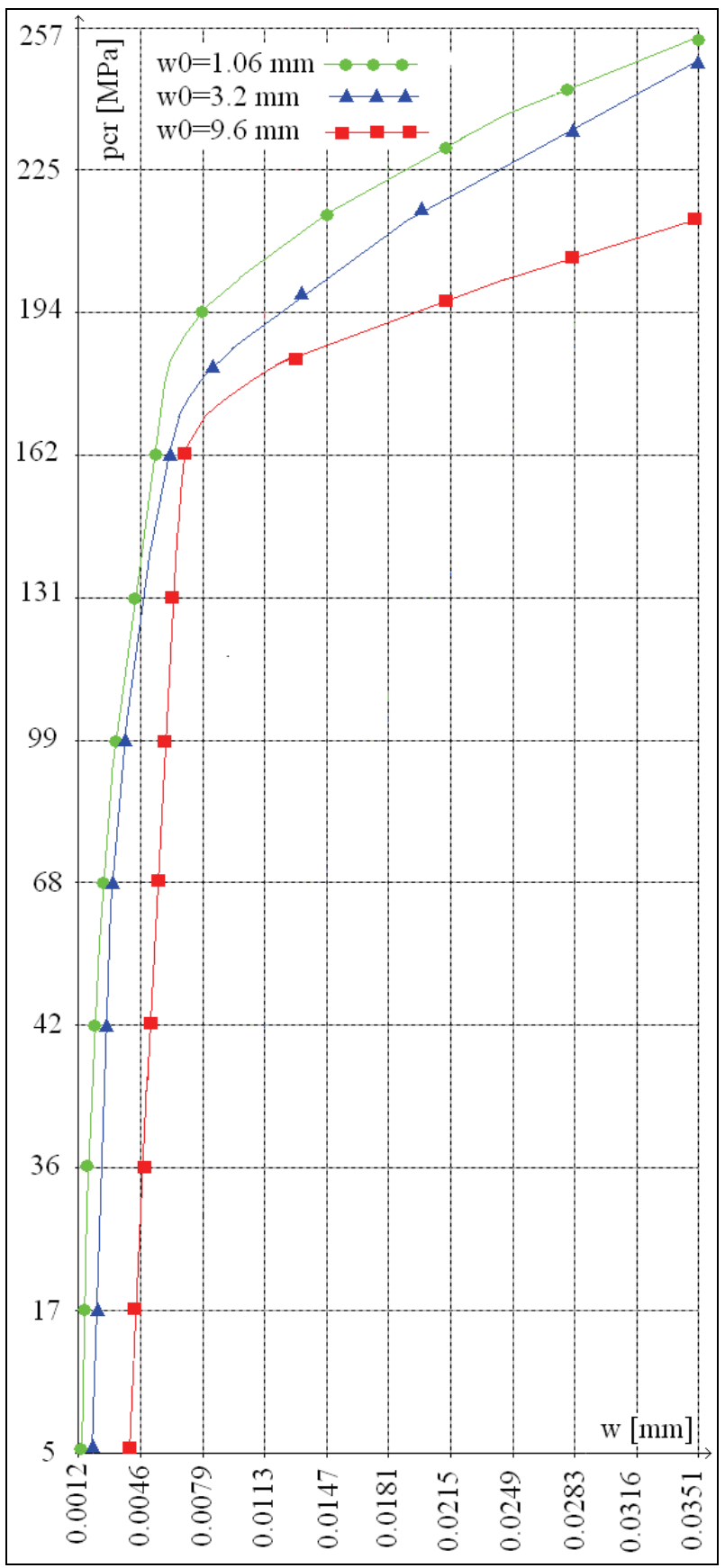

Fig. 17.4. Buckling and post buckling behaviour of compression buckling of plate with transversal imperfection 


\begin{tabular}{|l|l|l|}
\hline Macro-layer & $\alpha$ & $\mathrm{t}[\mathrm{mm}]$ \\
\hline \multirow{4}{*}{1} & $2 \times 0^{0}$ & 0.62 \\
\cline { 2 - 3 } & $45^{0}$ & 0.31 \\
\cline { 2 - 3 } & $2 \times 90^{0}$ & 0.62 \\
\cline { 2 - 3 } & $45^{0}$ & 0.31 \\
\cline { 2 - 3 } & $2 \times 0^{0}$ & 0.62 \\
\hline \multirow{4}{*}{2} & $2 \times 0^{0}$ & 0.62 \\
\cline { 2 - 3 } & $45^{0}$ & 0.31 \\
\cline { 2 - 3 } & $2 \times 90^{0}$ & 0.62 \\
\cline { 2 - 3 } & $45^{0}$ & 0.31 \\
\cline { 2 - 3 } & $2 \times 0^{0}$ & 0.62 \\
\hline
\end{tabular}

Table 17.1. Plate lay-up

The explanation is that due to the initial deformation, the in-plane loading produces the compression in the plate and also bending in the area of imperfection. Therefore it is difficult to determine the buckling load by numerical way.

This is why we have chosen the graphical method, by drawing the asymptote to the curve in the area where the slope is changing almost suddenly.

The intersection of the asymptote with the loading axis can be considered as buckling load. Anyway the asymptote is not an unique one and we may determine the buckling loading in a range of values. Also, according to the curves the buckling load is decreasing since the amplitude of the imperfection is increasing.

So, as it is seen in figure AA4, according to the plotted asymptotes, the buckling loads of the pates are placed in the domain

$140 \mathrm{MPa}<\mathrm{p}_{\mathrm{cr}}<175 \mathrm{MPa}$.

On the other part, we can determine the behaviour of the plate after the buckling (so name post-buckling behaviour), to estimate the ultimate capacity (ultimate strength) using one of the failure criteria. So, the in-plane loading value of first fail occurring in the material may be considered as the ultimate strength of the plate.

In the studies described in this chapter, the occurring of the first fail was done according to the Tsai-Wu failure criterion. Due to the elasticity of the thin plate, no any fail occurs for the in-plane pressure increasing up to the $260 \mathrm{MPa}$.

\subsection{Experimental studies on compression buckling}

The experiments were performed on plates having an initial transversal deformation with magnitude of $9.6 \mathrm{~mm}$ to determine the results obtained by numerical tests, such as:

- variation of the transversal displacement $(\mathrm{w})$ of the point placed in the middle of the plate, on the surface, function of in-plane loading magnitude $(p)$;

- variation of the strains in the certain point placed so on the concave face and on the convex face of the plate.

The measurements were done with the stretching machine, displacement transducer, strain gauge measurement system. In figure AA5, the plate and equipment used for experiments are shown. 


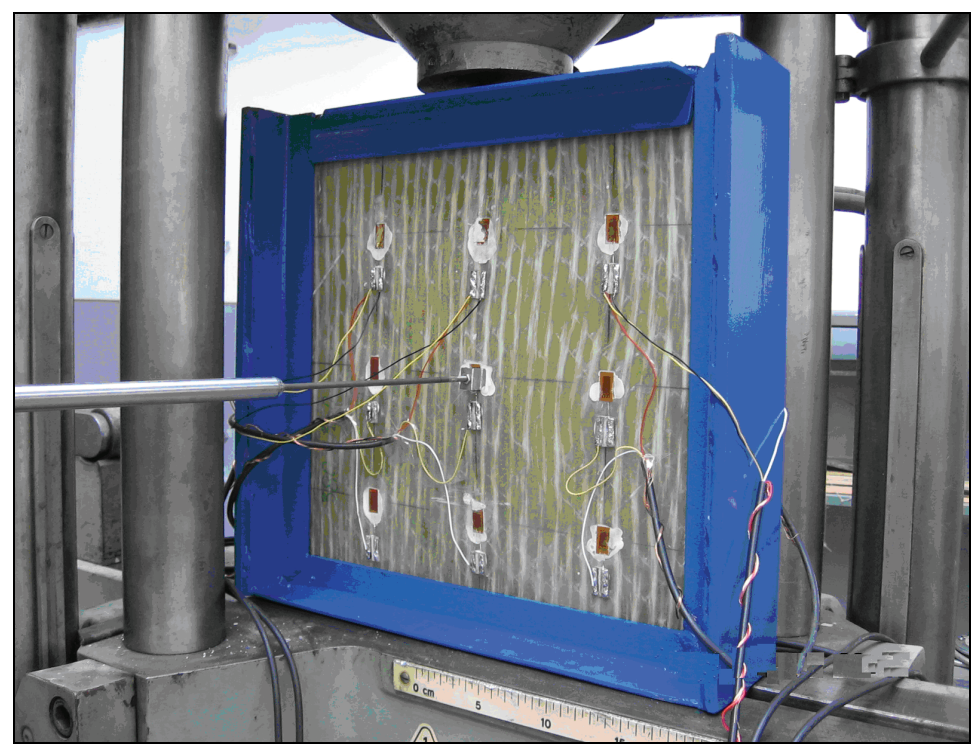

Fig. 17.5. Test rig and imperfect composite plate

To assure the boundary condition on the plate sides a special very rigid frame was made. So, the plate is clamped on three sides and simple supported on the side where the pressure is acting.

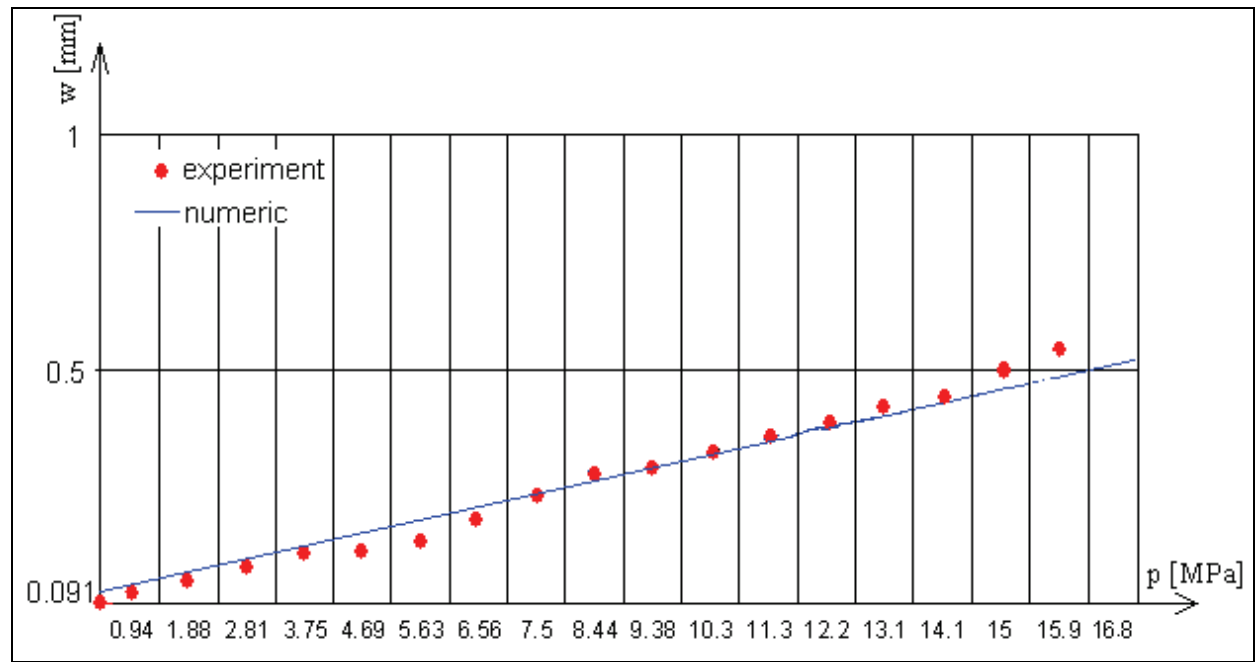

Fig. 17.6. Variation of compression load versus displacement of the point placed in the middle of the plate 
In the figure AA6, the results obtained from experiments are plotted with dots. Acceptable deviations between numerical and experimental results, for the transversal displacement of the point placed in the middle of the plate, are observed. In the figures only the elastic range of the curve is presented, because the experiment was made in this domain. In the abscise, a gap for pression corresponds to a force $\Delta \mathrm{F}=1 \mathrm{kN}$.

\subsection{Numerical studies on shearing buckling}

The geometry of the plates is square one, having the side length of $320 \mathrm{~mm}$, and total thickness of $4.96 \mathrm{~mm}$. The orthotropic directions $(\alpha)$, thickness of the macro-layers $(t)$ and plate lay-up are presented in Table AA1. The layers were grouped into the macro-layers (group of layers having the same characteristics: thickness $(t)$, direction of fibers $(\alpha)$ and type of material).

The constrains are considered according to plate presented in the previous chapter. The loading acting on the plate is according to figure AA7.

The all types of amplitude of initial transversal deformation have been analysis.

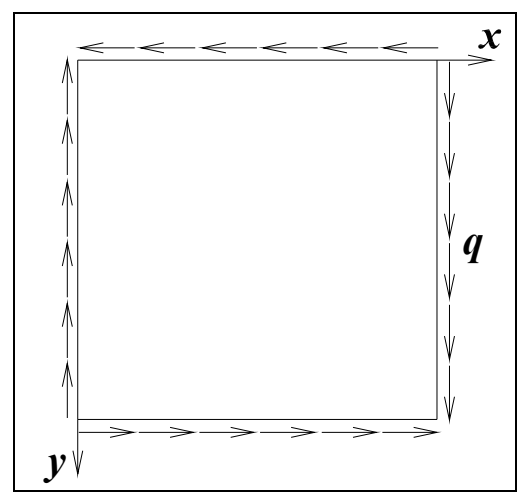

Fig. 17.7. Plate in shearing

In the table AA2 the buckling loads so for perfect and for imperfect plates are presented.

As it is seen, according to the graphical method, the buckling loads for the all three imperfect plates are in the range $104 \mathrm{MPa}<\mathrm{p}_{\mathrm{cr}}<275.78 \mathrm{MPa}$. As it is seen in figure AA8, the buckling load is decreasing since the magnitude of the transversal imperfection is increasing. In this case, the load capacity of the plate is decreasing since the transversal deformation of the plate is increasing.

But, after the nonlinear calculus according to Tsai-Wu criterion, the ultimate strength, presented in table AA2, may be considered as buckling load, due to the fact the values of the ultimate strength are almost constant for all plates $(15 \mathrm{MPa})$.

\begin{tabular}{|c|c|c|c|c|}
\hline Failure type & Perfect plate & $\mathrm{w}_{0}=1.06 \mathrm{~mm}$ & $\mathrm{w}_{0}=3.2 \mathrm{~mm}$ & $\mathrm{w}_{0}=9.6 \mathrm{~mm}$ \\
\hline FAIL 1 (tension) & 20 & 15 & 15 & 15 \\
\hline
\end{tabular}

Table 17.2. Shear buckling load (ultimate strength) in [MPa] 


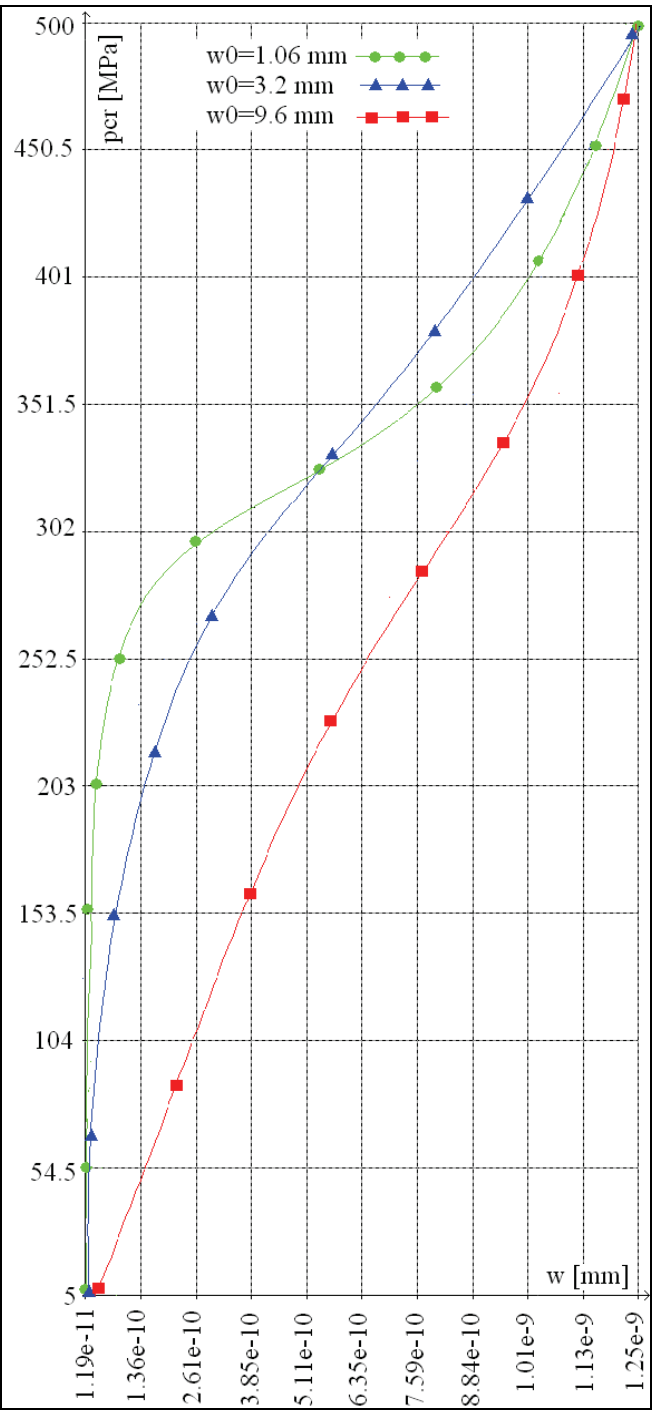

Fig. 17.8. Shear buckling and post buckling behaviour of the imperfect plate

\subsection{Numerical studies on combined (compression and shear) buckling}

The compression and shear buckling analysis is made only for thin plates (with material characteristics presented in previous chapter). The geometry of the plates is square one, having the side length of $320 \mathrm{~mm}$, and total thickness of $4.96 \mathrm{~mm}$. The orthotropic directions $(\alpha)$, thickness of the macro-layers $(t)$ and plate lay-up are presented in Table AA1.

The constrains are considered according to plates type $b$ from the previous chapter. The loading acting on the plate is according to figure AA9. For analysis the parametric calculus was done for various ratios $a=q / p$, that is $\{0.2 ; 0.4 ; 0.6 ; 0.8 ; 1\}$. 
The all types of amplitude of initial transversal deformation are analysed.

In the table AA3 the buckling loads so for perfect and for imperfect plates are presented.

Only the cases of $a=0.2$ and $a=0.4$ are presented in figure AA10. As it is seen in figure AA10, according to the graphical method, the buckling loads for the all three imperfect plates are in the range $0.134 \mathrm{MPa}<\mathrm{p}_{\mathrm{cr}}<0.288 \mathrm{MPa}$.

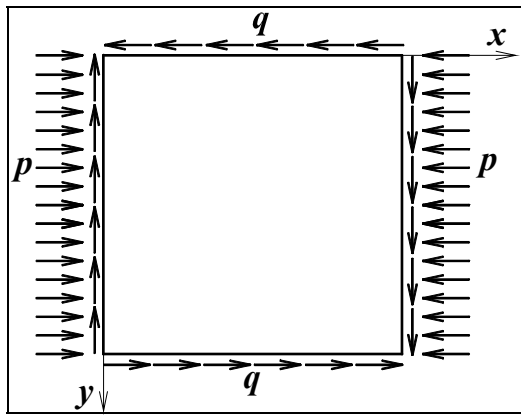

Fig. 17.9. Plate in shearing and compression

\begin{tabular}{|c|c|c|c|c|}
\hline$a=q / p$ & $\mathrm{w}_{0}=0$ & $\mathrm{w}_{0}=1.06 \mathrm{~mm}$ & $\mathrm{w}_{0}=3.2 \mathrm{~mm}$ & $\mathrm{w}_{0}=9.6 \mathrm{~mm}$ \\
\hline 0.2 & 41.765 & 0.288 & 0.222 & 0.134 \\
\hline 0.4 & 41.561 & 0.266 & 0.111 & 0.087 \\
\hline 0.6 & 41.007 & 0.288 & 0.088 & 0.071 \\
\hline 0.8 & 40.167 & 0.277 & 0.111 & 0.071 \\
\hline 1 & 39.119 & 0.305 & 0.124 & 0.081 \\
\hline
\end{tabular}

Table 17.3. Buckling load in [MPa] for shearing and compression loading of plate

\begin{tabular}{|c|c|c|c|c|c|}
\hline$a=q / p$ & $\begin{array}{c}\text { Failure } \\
\text { mode }\end{array}$ & $\begin{array}{c}\text { Perfect } \\
\text { plate }\end{array}$ & $\mathrm{w}_{0}=1.06 \mathrm{~mm}$ & $\mathrm{w}_{0}=3.2 \mathrm{~mm}$ & $\mathrm{w}_{0}=9.6 \mathrm{~mm}$ \\
\hline \multirow{2}{*}{0.2} & Tension & 2.499 & 0.706 & 0.605 & 0.403 \\
\cline { 2 - 6 } & Compression & - & 1.413 & 1.312 & 1.211 \\
\hline \multirow{2}{*}{0.4} & Tension & 2.499 & 0.706 & 0.504 & 0.403 \\
\cline { 2 - 6 } & Compression & - & 1.311 & 1.211 & 0.999 \\
\hline \multirow{2}{*}{0.6} & Tension & 1.874 & 0.504 & 0.504 & 0.302 \\
\cline { 2 - 6 } & Compression & - & 0.908 & 0.876 & 0.802 \\
\hline \multirow{2}{*}{0.8} & Tension & 1.562 & 0.403 & 0.403 & 0.302 \\
\cline { 2 - 6 } & Compression & - & 0.806 & 0.706 & 0.706 \\
\hline \multirow{2}{*}{1} & Tension & 1.249 & 0.302 & 0.302 & 0.302 \\
\cline { 2 - 6 } & Compression & - & 0.706 & 0.563 & 0.563 \\
\hline
\end{tabular}

Table 17.4. Buckling load (ultimate strength) in [MPa] for shearing and compression loading of plate 
As it is seen in figure AA10, the buckling load is decreasing since the magnitude of the transversal imperfection is increasing for all cases of loading ratios (see also table AA3).

In this case, the load capacity of the plate is decreasing since the transversal deformation of the plate is increasing. According to the nonlinear calculus (according to Tsai-Wu criterion), the ultimate strength is presented in table AA4.

The ultimate strength (pression corresponding to the first fail occurring) for perfect plates is greater than the ultimate strength of the plate with transversal imperfection.

In the central area, in the layers the compression fails occurs at an in-plane pression greater than the pression corresponding to tension fails.

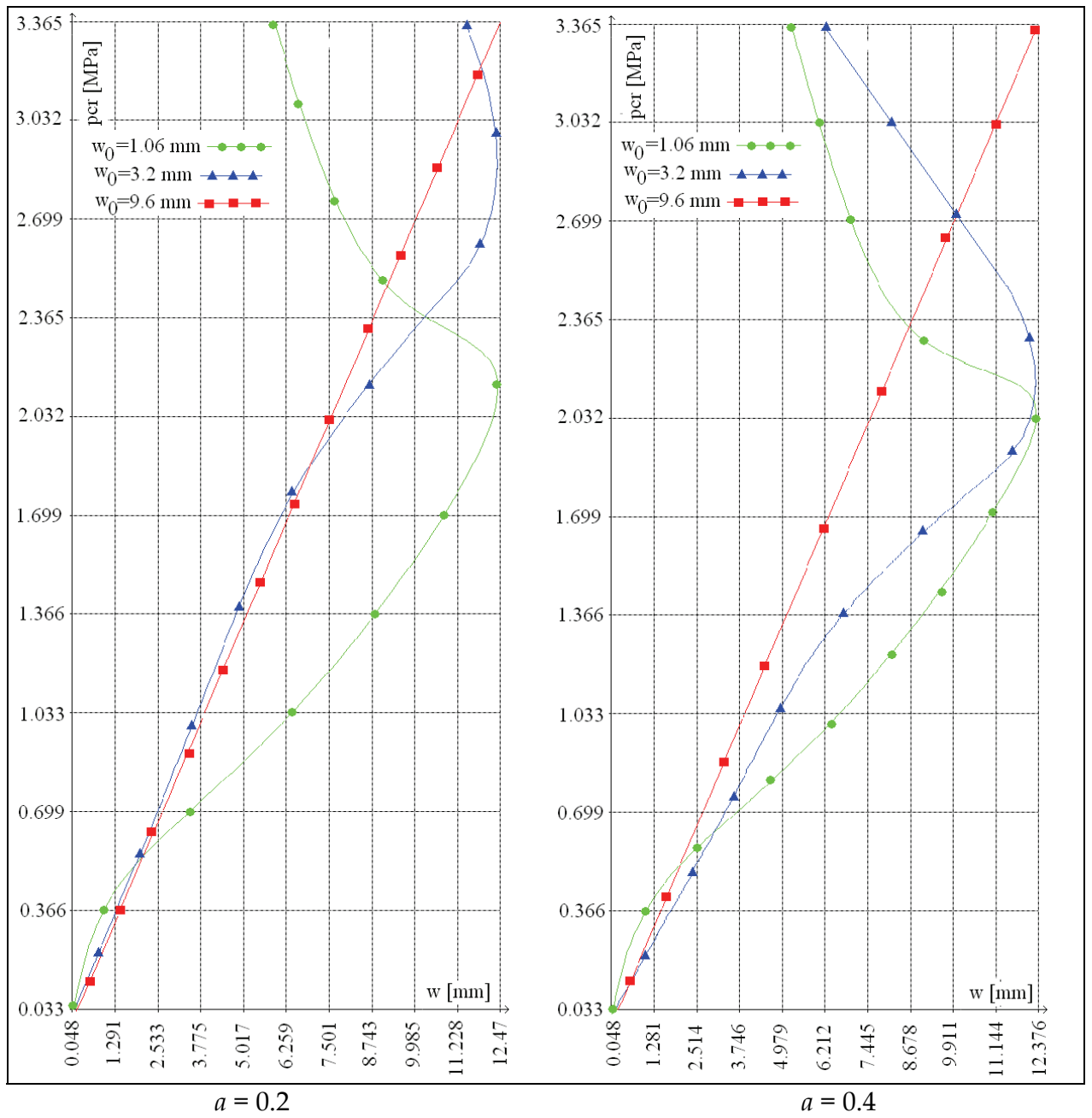

Fig. 17.10. Shear and compression behaviour of the plate

The ultimate strength decreases since the transversal imperfection is increasing. 
The tension fails occur in a corner of the plate. On the other part, the compression fails occur in the central part (imperfection area) of the plate.

\subsection{Conclusions for buckling of plates with transversal imperfections}

The FEM based methodology and the experimental test program were successfully developed for the investigation of buckling problems of composite plates. The FEM model is robust in that it can be used to predict the global buckling loads of composite plates either on one side or both sides. Finite-elements analysis and experimentation were carried out to assess the reliability of the methodology. The buckling behaviour of the orthotropic composite plates is different than the buckling behaviour of the isotropic plates. A special remark is to do for the plates having initial transversal deformation: the transversal deformation is increasing since the in-plane load starts to increase.

The buckling load determination is too difficult without applying a graphical method, or applying the Tsai-Wu failure criterion.

So, for a plate with transversal imperfection, since the magnitude of the initial transversal deformation is increasing, the value of the force for compression failure or tension failure of an element is decreasing.

The lack of the criterion is referring to the anticipation of the real mode to occurring the cracking.

Taking into account the mathematical formulation, the Tsai-Wu failure criterion is easy to be applied. Additionally, this criterion offers advantages concerning the real prediction of the strength at variable loadings. It is to remark that by applying linear terms, it is possible to take into account the differences between the tension and compression strengths of the material.

A good correlation between the numerical and experimental results is concluded.

\section{Finite element modelling of delaminated composite plates}

\subsection{Presentation}

Due to the anisotropy of composite laminates and non-uniform distribution of stresses in lamina under flexural bending as well as other types of static/dynamic loading, the failure process of laminates is very complex.

Large differences in strength and stiffness values of the fiber and the matrix lead to various forms of defect/damage caused during manufacturing process as well as service conditions. In shipbuilding, many structures made of composite laminates are situated such that they are susceptible to foreign object impacts which can result in barely visible impact damage. Often, in the form of a complicated array of matrix cracks and interlaminar delaminations, these barely visible impact damages can be quite extensive and can significantly reduce a structure's load bearing capability.

Delamination or separation of two adjacent plies in a composite laminate is one of the most common modes of damage. The presence of delamination may reduce the overall stiffness as well as the residual strength leading to structural failure. A clear understanding of the influence of delamination on the performance of the laminates is very essential to use them efficiently in structural design applications.

Since such damage is in general difficult to detect, structures must be able to function safely with delamination present. 
Although several studies are available in the literature in the field of delamination prediction and growth, effect of delamination on buckling, post-buckling deformation and delamination propagation under fatigue loading, etc. the work on the effect of delamination on the first ply failure of the laminate is scarce.

However, there clearly exists the need to be able to predict the tolerance of structures to damage forms which are not readily detectable (Chirica \& al, 2006).

(Ambarcumyan, 1991, Adams \& al, 2003) have analysed experimental characterization of advanced composite materials. When a laminate is subjected to in-plane compression, the effects of delamination on the stiffness and strength may be characterized by three sets of results, (Finn \& Springer, 1993):

a. Buckling load;

b. Postbuckling solutions under increased load;

c. Results concerning the onset of delamination growth and its subsequent development.

Many of the analytical treatments deal with a thin near surface delamination. Such approaches are known as "thin-film" analysis in the literature (Kim \& al,1999, Thurley \& al, 1995). The thin-film analytical approach may involve significant errors in the post-buckling solutions.

(Naganarayana \& Atluri, 1995) have analysed the buckling behaviour of laminated composite plates with elliptical delaminations at the centre of the plates using finite element method. They propose a multi-plate model using 3-noded quasi-conforming shell element, and use J-integral technique for computing point wise energy release rate along the delamination crack front.

(Pietropaoli \& al, 2008) studied delamination growth phenomena in composite plates under compression by taking into account also the matrix and fibers breakages until the structural collapse condition is reached.

The aim of the work presented in this chapter is to present the studies on the influence of elliptical delamination on the changes in the buckling behaviour of ship deck plates made of composite materials. This problem has been solved by using the finite element method, in (Beznea, 2008). An orthotropic delamination model, describing mixed mode delaminating, by using FEM analysis, was applied. So, the damaged part of the structures and the undamaged part have been represented by well-known finite elements (layered shell elements). The influence of the position and the ellipse's diameters ratio of delaminated zone on the critical buckling force was investigated.

If an initial delamination exists, this delamination may close under the applied load. To prevent the two adjacent plies from penetrating, a simple numerical contact model is used.

Taking into account the thickness symmetry of the plates, only cases of position of delamination on one side of symmetry axis are presented. The variations of the transversal displacement of the point placed in the middle of the plate versus the in-plane applied pressure are plotted for each position of delamination. Buckling load determination for the general buckling of the plate has been done by graphical method. The post-buckling calculus has been performed to explain the complete behaviour of the plate.

Only cases with one delamination placed between two laminas is presented here.

There are several ways in which the panel can be modeled for the delamination analysis. For the present study, a 3-D model with 4-node shell composite elements is used. The plate is divided into two sub-laminates by a hypothetical plane containing the delamination. For this reason, the present finite element model would be referred to as two sub-laminates 
model. The two sub-laminates are modeled separately with shell composite elements, and then joined face to face with appropriate interfacial constraint conditions for the corresponding nodes on the sub-laminates, depending on whether the nodes lie in the delaminated or undelaminated region.

The delamination model has been developed by using the surface-to-surface contact option (Fig. AA11). In case of surface-to-surface contact, the FE meshes of adjacent plies do no need to be identically. The contact algorithm used in the FEM analysis has possibility to determine which node of the so-called master surface is in contact with a given node on the slave surface. Hence, the user can define the interaction between the two surfaces.

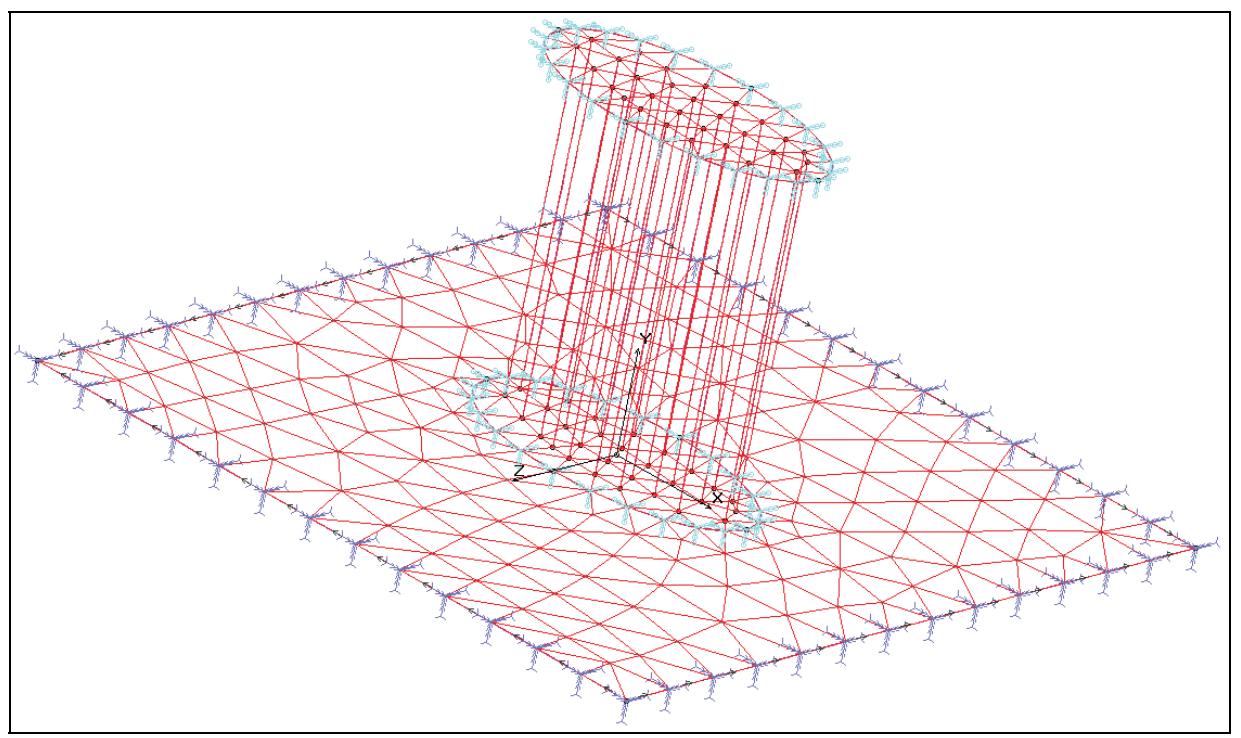

Fig. 17.11. The FEM delamination model

The condition is that the delaminated region does not grow. These regions were modeled by two layers of elements with coincident but separate nodes and section definitions to model offsets from the common reference plane. Thus their deformations are independent. At the boundary of the delamination zones the nodes of one row are connected to the corresponding nodes of the regular region by master slave node system.

Typically, a node in the underlaminated region of bottom sub-laminate and a corresponding node on the top sub-laminate are declared to be coupled nodes using master-slave nodes facility. The nodes in the delaminated region, whether in the top or bottom laminate, are connected by contact elements. This would mean that the two sublaminates are free to move away from each other in the delaminated region, and constrained to move as a single laminate in the undelaminated region.

The material characteristics presented in previous chapter are used.

Two material models were used: quasi-nonlinear model and non linear model.

A quasi-nonlinear model means that the material behaviour is not according to a failure criterion.

The non-linear model is the material fulfilling Tsai-Wu failure Criterion. 
The ellipse's diameters of the delamination area placed in the middle of the plate are considered from the condition of the same area for all cases. In the parametric calculus, the following diameters ratios were considered:

- Case 1 (Dx/Dy=0.5): transversal diameter $\mathrm{Dy}=141 \mathrm{~mm}$, longitudinal diameter $\mathrm{Dx}=70.5 \mathrm{~mm}$;

- Case $2(\mathrm{Dx} / \mathrm{Dy}=1)$ : transversal diameter $\mathrm{Dy}=100 \mathrm{~mm}$; longitudinal diameter $\mathrm{Dx}=100 \mathrm{~mm}$;

- Case $3(\mathrm{Dx} / \mathrm{Dy}=2)$ : transversal diameter $\mathrm{Dy}=70.5 \mathrm{~mm}$; longitudinal diameter $\mathrm{Dx}=141 \mathrm{~mm}$.

In this chapter the following cases (in numerical and experimental ways) are presented: compressive buckling, shear buckling, mixed compressive and shear buckling. The results (for linear, and nonlinear model) are presented as variation of the buckling loads function of maximum transversal displacement (buckling and post-buckling behaviour).

The buckling analysis of delaminated plates was done on square plates $(320 \times 320 \mathrm{~mm})$, made of E-glass/epoxy (biaxial layers having the thickness $\mathrm{t}=0.32 \mathrm{~mm}$ ).

These layers are grouped into macro-layers as are presented in table AA1. The position of the delamination is considered between two neighbors layers $i$ and $i+1,(i=1,10)$. The calculus was done for the all 9 cases. Only results obtained for a specific case of position of delamination $(\mathrm{i}=4)$ are presented in the chapter.

\subsection{Numerical studies on compression buckling}

The plate is considered as clamped on the sides. The in-plane loading was applied as an uniform compressive pressure in the $x$ direction (Fig. AA12). The force was increased step by step (with and certain increment). In the figure AA13, the variation of the transversal displacements of the central point, versus applied loading is drawn. Each curve corresponds to one diameters ratio.

Buckling load has been determined by the graphical method. On each curve that corresponds to a delamination type, an asymptote on curve after the bifurcation has been plotted. Critical value for the buckling load was obtained in the range:

$43.41 \mathrm{MPa}<\mathrm{p}_{\mathrm{cr}}<59.5 \mathrm{MPa}$

In the case of nonlinear model of the material behaviour the buckling load (ultimate strength) was determined by Tsai Wu criterion. So, the degradation index (failure index) for tension and compression of the delaminated plates was determined (Table AA7). Only the plate global buckling was examined.

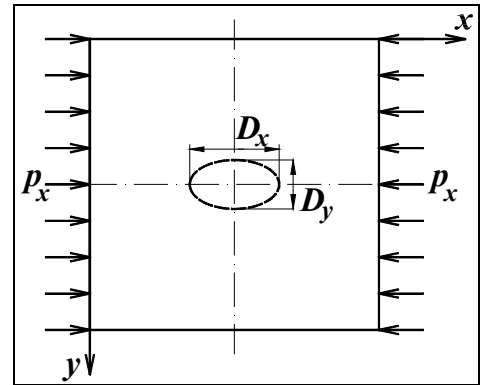

Fig. 17.12. Delaminated plate with in-plane loading 


\begin{tabular}{|c|c|c|}
\hline Failure mode & Fail 1 (Tension) & Fail 2 (Compression) \\
\hline $\mathrm{Dx} / \mathrm{Dy}=0.5$ & 35 & 74 \\
\hline $\mathrm{Dx} / \mathrm{Dy}=1$ & 37 & 78 \\
\hline $\mathrm{Dx} / \mathrm{Dy}=2$ & 39 & 82 \\
\hline
\end{tabular}

Table 17.5. Buckling load (ultimate strength) in [MPa] for compression loading

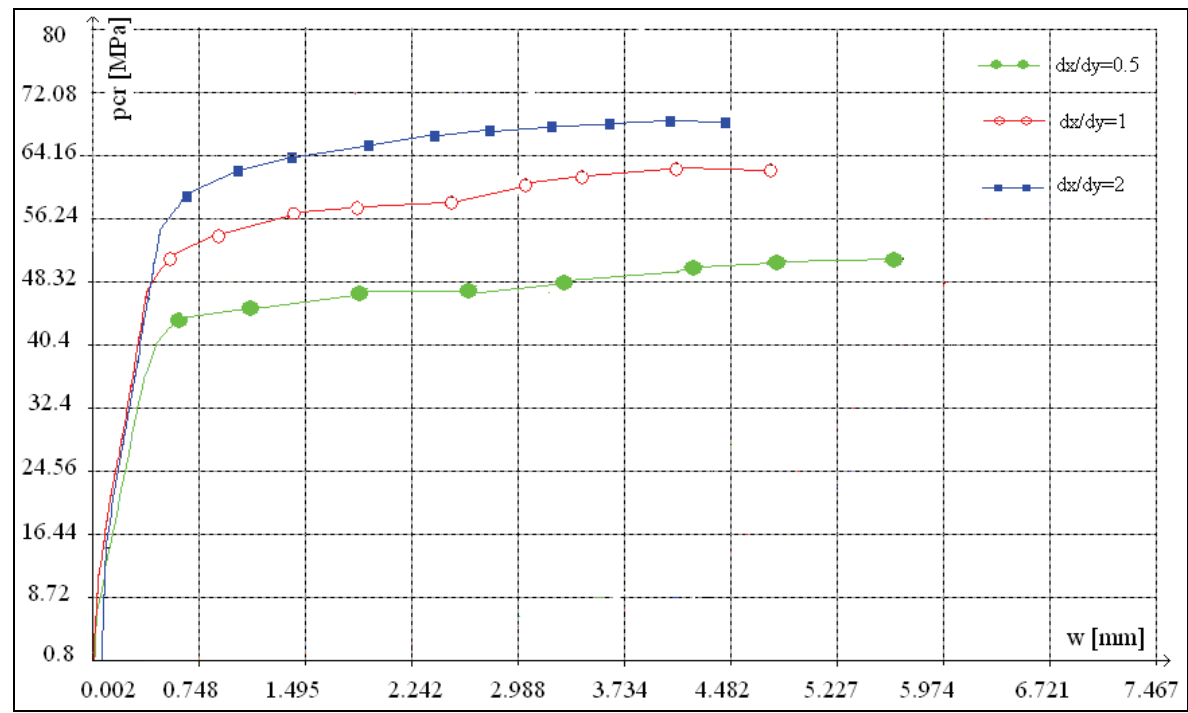

Fig. 17.13. Compression buckling and post buckling behaviour of the plates with central delamination placed between macro-layers 4 and 5

\subsection{Numerical studies on shearing buckling}

\subsubsection{Shearing buckling of thin plates}

In this chapter, the thickness and the lay-up of the plate are according to Table AA1. The plate, considered as clamped on the sides, was loaded with an uniform shear pressure on the sides (Fig. AA14). The force was increased step by step (with and certain increment).

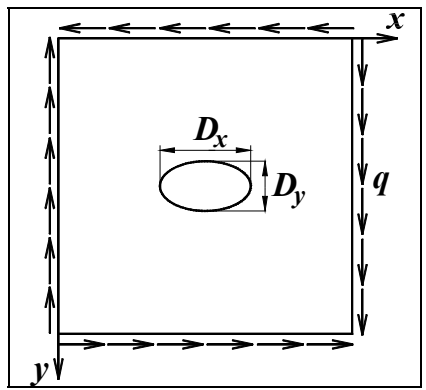

Fig. 17.14. Shear loaded plate with central delamination 
In the figure AA15, the variation of the transversal displacements of the central point, versus applied loading is drawn, for delamination placed between macro-layers 4 and 5 . Each curve corresponds to one diameters ratio.

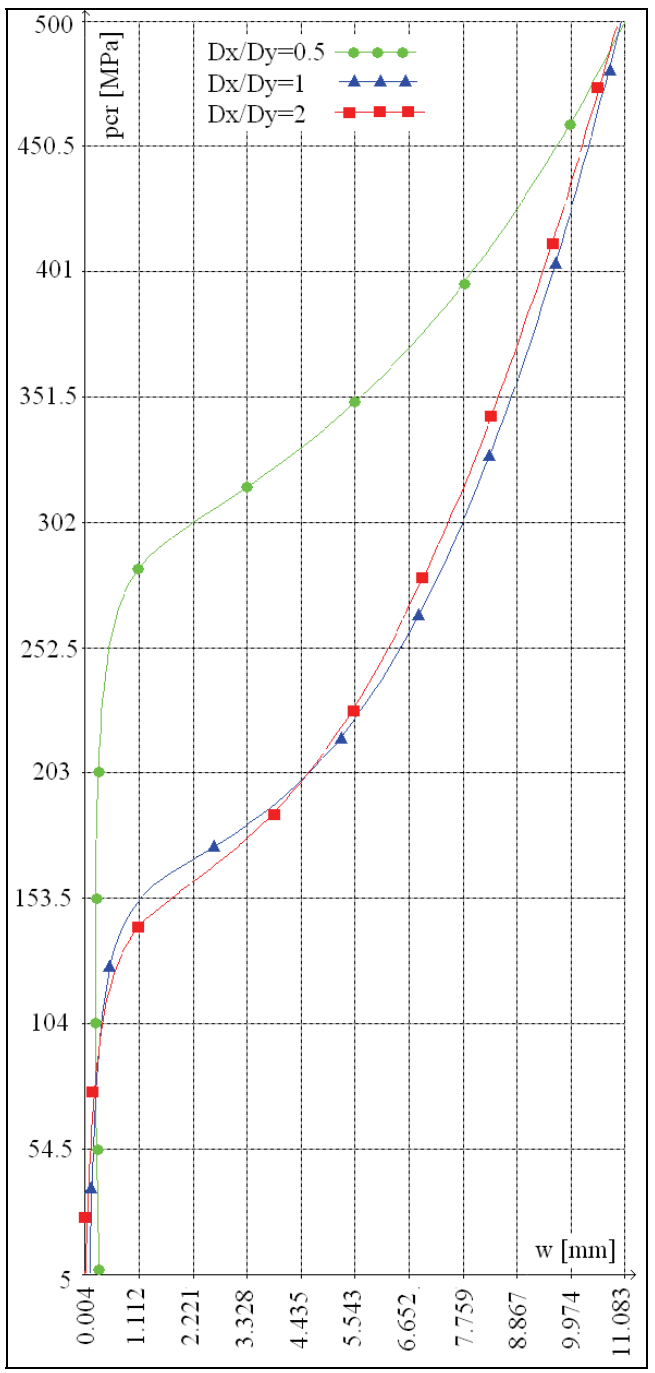

Fig. 17.15. Shear buckling and post buckling behaviour of the plates with central delamination placed between macro-layers 4 and 5

Buckling load has been determined by the graphical method (an asymptote on curve after the bifurcation has been plotted).

Critical value for the buckling load was obtained in the range $109 \mathrm{MPa}<\mathrm{p}_{\mathrm{cr}}<289 \mathrm{MPa}$.

In the case of nonlinear model of the material behaviour the buckling load (ultimate strength) was determined by Tsai Wu criterion. So, the degradation index (failure index) for 
tension and compression of the delaminated plates was determined (Table AA6). Only the plate global buckling was examined.

\begin{tabular}{|c|c|c|c|c|}
\hline \multicolumn{2}{|c|}{ Dx/Dy } & \multirow{2}{*}{0.5} & 1 & 2 \\
\hline Position of delamination & Fail type & & & \\
\hline Macro-layer 1 & Traction & 25 & 20 & 20 \\
\cline { 2 - 5 } Macro-layer 2 & Compression & 90 & - & - \\
\hline Macro-layer 2 & Traction & 25 & 20 & 20 \\
\cline { 2 - 5 } Macro-layer 3 & Compression & 90 & - & - \\
\hline Macro-layer 3 & Traction & 25 & 20 & 20 \\
\cline { 2 - 5 } Macro-layer 4 & Compression & 90 & - & - \\
\hline Macro-layer 4 & Traction & 25 & 20 & 20 \\
\cline { 2 - 5 } Macro-layer 5 & Compression & 90 & - & - \\
\hline
\end{tabular}

Table 17.6. Buckling load (ultimate strength) in [MPa] for shear loading of the plates

\subsection{Numerical studies on combined (compression and shear) buckling}

The discussions and results on compression and shear buckling analysis will be done only for plate presented in figure AA9, having the same geometry and the orthotropic directions $(\alpha)$, thickness of the macro-layers $(t)$ and plate lay-up according to Table AA1.

For analysis the calculus was done for various ratios $a=q / p$, that is $\{0.2 ; 0.4 ; 0.6 ; 0.8 ; 1\}$.

In figure AA16 the combined loading (shear and compression) buckling and post buckling behaviour of the plates with central delamination placed between macro-layers 1 and 2, for $a=0.2$ is presented.

\begin{tabular}{|c|c|c|c|c|c|}
\hline$a=q / p$ & Failure mode & Perfect plate & Dx/Dy=0.5 & Dx/Dy=1 & Dx/Dy=2 \\
\hline \multirow{2}{*}{0.2} & Tension & 3962 & 3.962 & 3.962 & 4.239 \\
\cline { 2 - 6 } & Compression & 8.879 & 8.059 & 7.649 & 6.147 \\
\hline \multirow{2}{*}{0.4} & Tension & 3.688 & 3.688 & 3.688 & 4.098 \\
\cline { 2 - 6 } & Compression & 7.649 & 6.966 & 6.966 & 5.874 \\
\hline \multirow{2}{*}{0.6} & Tension & 3.142 & 3.005 & 2.868 & 2.868 \\
\cline { 2 - 6 } & Compression & 6.966 & 6.693 & 5.601 & 5.191 \\
\hline \multirow{2}{*}{0.8} & Tension & 2.868 & 2.322 & 2.049 & 2.049 \\
\cline { 2 - 6 } & Compression & 6.693 & 6.425 & 6.425 & 5.327 \\
\hline \multirow{2}{*}{1} & Tension & 1.912 & 1.912 & 1.639 & 1.639 \\
\cline { 2 - 6 } & Compression & 6.147 & 4.508 & 4.508 & 4.508 \\
\hline
\end{tabular}

Table 17.7. Buckling load in [MPa] for shearing and compression loading

According to the curves presented in figure AA16 the buckling load is decreasing since the value of the diameters ratio is increasing.

So, as it is seen in figure AA16, according to the plotted asymptotes, the buckling loads of the thin plates are placed in the domain

$0.368 \mathrm{MPa}<\mathrm{p}_{\mathrm{cr}}<2.634 \mathrm{MPa}$.

In the case of nonlinear model of the material behaviour, the buckling load (ultimate strength) was determined by Tsai Wu criterion, so that the degradation index (failure index) for tension and compression of the delaminated plates may be shown in Table AA7. 


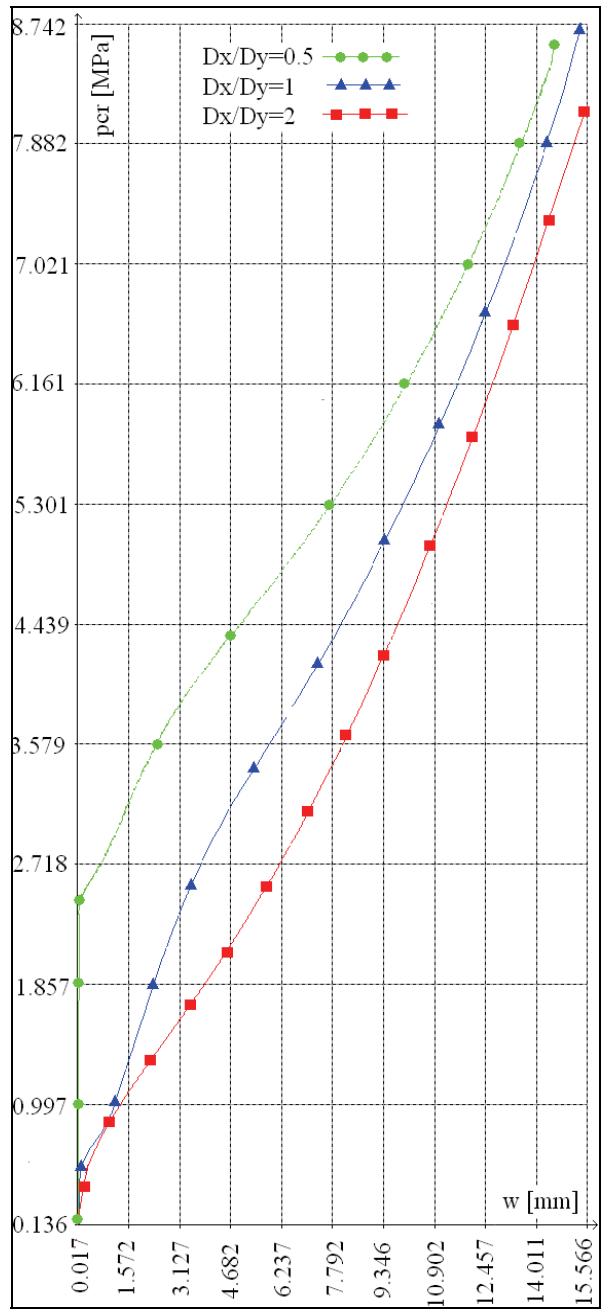

Fig. 17.16. Buckling and post buckling behaviour of the plate

\subsection{Conclusions for buckling of plates with delaminations}

Delamination is a phenomenon of critical importance for the composite industry. It involves a breakdown in the bond between the reinforcement and the matrix material of the composite. Understanding delamination is essential for preventing catastrophic failures. Due to the geometry and general load of the ship deck, buckling is one of the most important failure criteria. The FEM based methodology was successfully developed for the investigation of buckling problems of composite plates having a central delamination. Two hypotheses regarding the type of material modeling were used: linear and nonlinear model. In the chapter, a convenient methodology to model delaminated composite plates was presented. The FEM modeling can be used to predict the global buckling loads of composite plates with delaminations. 
In the case of linear model used for material, the following conclusions can be formulated:

- For the values of in-plane loads lower than $40 \mathrm{MPa}$, the displacement values are increasing since the diameters ratio is increasing. This trend is due to the fact the transversal diameter is decreasing (since the delaminated area remains constant). Smaller transversal diameter means increasing of shear stiffness.

- In the case of the in-plane loading values bigger than $40 \mathrm{MPa}$, the displacement values are decreasing since the diameters ratio is increasing. This trend is due to the contact pressure between the layers in contact in the delamination, which is increasing since the loading force is increasing.

In the case of nonlinear material model (Figure AA13) the trend of the curves is so that the transversal displacement is increasing since the diameters ratio is increasing for the same inplane loading, for a in-plane loading value under 25-40 MPa. For an in-plane loading value between 40 and $65 \mathrm{MPa}$ in each case, a small instant jumping of transversal displacement is observed. This means that what is recover in plate stiffness after the increasing of contact pression in the delamination area, is lost due to the lamina damage occurring.

The buckling load determination is too difficult without the applying a graphical method, or the applying the Tsai- $\mathrm{Wu}$ failure criterion in the case of the general buckling not occurred till the first-ply failure occurring.

The first failure occurring in an element is based on the Tsai-Wu failure criterion, which provides the mathematical relation for strength under combined stresses was used.

The failure index is calculated in each ply of each element. In the ply where failure index is greater than 1, the first-ply failure occurs, according to the Tsai-Wu criterion. In the next steps, the tensile and compressive properties of this element are reduced by the failure index. If the buckling did not appeared until the moment of the first-ply failure occurring, the in-plane load corresponding to this moment is considered as the buckling load.

The lack of the criterion is referring to the anticipation of the real mode to occurring the cracking.

Taking into account the mathematical formulation, the Tsai-Wu failure criterion is easy to be applied. Additionally, this criterion offers advantages concerning the real prediction of the strength at variable loadings. In the case of shear buckling of thin plates, the ultimate strength of the delaminated plate is not depending on the position of delamination. For diameters ratio greater than 1, the ultimate strength in shear loading occurs only for traction fail.

Final remarks may be done. A very good postbuckling load carrying ability specific to light weight structures can be exploited to obtain high performance. Finite element analysis can offer more accurate analyses with a high degree of fidelity.

Since the plates included in the ship hull structure (so perfect or imperfect) are subjected to in-plane forces combined with transverse pressure, the buckling response of such plates is a basic concern in the design process. Furthermore, the presence of imperfections may weaken the load-carrying capacity of structures due to stiffness loss and cause an increase in stress concentrations in the imperfection area.

After the buckling, the composite plates, so perfect or imperfect, have a great capacity to be overloaded, so that the plate and finally the structure is not collapsed immediately.

\section{Acknowledgement}

The results presented in this chapter are based on the work supported by CNCSISUEFISCSU, project number PNII - IDEI, code 512/2008. 


\section{References}

Adams, D.F., Carlsson, L.A. \& Pipes, R.B. (2003). Experimental Characterization of Advanced Composite materials, Ed. Taylor \& Francis Group.

Altenbach, H., Altenbach, J. \& Kissing, W. (2004). Mechanics of Composite Structural Elements, Ed. Springer, Berlin.

Ambarcumyan, S.A: (1991). Theory of Anisotropic Plates: Strength, Stability, and Vibrations, Hemispher Publishing,Washington.

Beznea, E.F., (2008). Studies and Researches on the Buckling Behaviour of the Composite Panels, Doctoral Thesis, University Dunarea de Jos of Galati.

Beznea, E.F., \& Chirica, I.,(2009). Studies on buckling behaviour of the composite plates with delamination, Proceedings of the 26-th DAS-2009: Danubia-Adria Symposium on Development in Experimental Mechanics, Leoben, Austria, pp.13-14, ISBN 978-3902544-02-5

Bisagni, C. \& Cordisco, P., (2004). Testing of Stiffened Composite Cylindrical Shells in the Postbuckling Range until Failure, AIAA Journal, Vol. 42, No. 9, pp. 1808- 1817

Chirica, I., Beznea, E.F., Chirica, R., Boazu, D., Chirica, A. \& Berggreen C.C., (2008). Journal of Material Testers Magazine, www.anyagvizsgaloklapja.hu, Vol. 18/1, p. 24.

Chirica, I., Beznea, E.F.,\& Chirica, R., (2009). Studies on buckling of the ship deck panels with imperfections made of composite materials, Materiale Plastice, vol. 46, nr.3, , pp. 243-248, ISSN0025/5289

Engelstad, S. P., Reddy, J. N. \& Knight, N. F., Jr. (1992). Postbuckling Response and Failure Prediction of Graphite-Epoxy Plates Loaded in Compression, AIAA Journal, 30(8), 2106-2113

Finn, S.C. \& Springer, G.S. (1993). Delamination in Composites Plates under Transverse Static or Impact Loads-a model, Composite Structures, vol. 23

Hilburger, M.F. (2001). Nonlinear and Buckling Behavior of Compression-loaded Composite Shells, Proceedings of the 6th Annual Technical Conference of the American Society for Composites, Virginia.

Kawai, T. \& Ohtsubo, H. (1968). A Method of Solution for the Complicated Buckling Problems of ElasticPlates With Combined Use of Rayleigh-Ritz's Procedure in the Finite Element Method, AFFDLTR-68-150

Kim, H. \& Kedward, K.T., (1999). A Method for Modeling the Local and Global Buckling of Delaminated Composite Plates. Composite Structures 44: 43-53

Knight N. F. Jr. \& Starnes J. H. Jr., (1988). Postbuckling Behavior of Selected Curved Stiffened Graphite Epoxy Panels Loaded in Axial Compression, AIAA Journal, Vol. 26, No. 3, pp.344-352.

Naganarayana, B.P.\& Atluri, S.N. (1995). Strength Reduction and Delamination Growth in Thin and Thick Composite Plates under Compressive Loading, Computational Mechanics, 16: 170-189.

Pietropaoli, E., Riccio, A. \& Zarrelli, M., (2008). Delamination Growth and Fibre/Matrix Progresive Damage in Composite Plates under Compression. ECCM13, The 13-th European Conference on Composite Materials, June 2-5, Stockholm, Sweden

Schlack, A.L., Jr. (1964). Elastic Stability of Pierced Square Plates. Experimental Mechanics, June 167-172.

Thurley, G.J. \& Marshall, I.H. (1995). Buckling and Postbuckling of Composite Plates, Ed. Chapman \& Hall, London. 


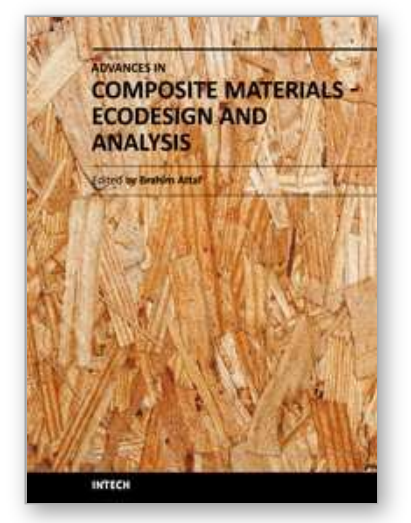

\author{
Advances in Composite Materials - Ecodesign and Analysis \\ Edited by Dr. Brahim Attaf
}

ISBN 978-953-307-150-3

Hard cover, 642 pages

Publisher InTech

Published online 16, March, 2011

Published in print edition March, 2011

By adopting the principles of sustainable design and cleaner production, this important book opens a new challenge in the world of composite materials and explores the achieved advancements of specialists in their respective areas of research and innovation. Contributions coming from both spaces of academia and industry were so diversified that the 28 chapters composing the book have been grouped into the following main parts: sustainable materials and ecodesign aspects, composite materials and curing processes, modelling and testing, strength of adhesive joints, characterization and thermal behaviour, all of which provides an invaluable overview of this fascinating subject area. Results achieved from theoretical, numerical and experimental investigations can help designers, manufacturers and suppliers involved with high-tech composite materials to boost competitiveness and innovation productivity.

\title{
How to reference
}

In order to correctly reference this scholarly work, feel free to copy and paste the following:

Elena-Felicia Beznea and Ionel Chirica (2011). Buckling and Post-buckling Analysis of Composite Plates, Advances in Composite Materials - Ecodesign and Analysis, Dr. Brahim Attaf (Ed.), ISBN: 978-953-307-150-3, InTech, Available from: http://www.intechopen.com/books/advances-in-composite-materials-ecodesign-andanalysis/buckling-and-post-buckling-analysis-of-composite-plates

\section{INTECH}

open science | open minds

\author{
InTech Europe \\ University Campus STeP Ri \\ Slavka Krautzeka 83/A \\ 51000 Rijeka, Croatia \\ Phone: +385 (51) 770447 \\ Fax: +385 (51) 686166 \\ www.intechopen.com
}

\author{
InTech China \\ Unit 405, Office Block, Hotel Equatorial Shanghai \\ No.65, Yan An Road (West), Shanghai, 200040, China \\ 中国上海市延安西路65号上海国际贵都大饭店办公楼 405 单元 \\ Phone: +86-21-62489820 \\ Fax: $+86-21-62489821$
}


(C) 2011 The Author(s). Licensee IntechOpen. This chapter is distributed under the terms of the Creative Commons Attribution-NonCommercialShareAlike-3.0 License, which permits use, distribution and reproduction for non-commercial purposes, provided the original is properly cited and derivative works building on this content are distributed under the same license. 